\title{
The Application of Restriction Landmark Genome Scanning Method for Surveillance of Non-Mendelian Inheritance in $\mathbf{F}_{1}$ Hybrids
}

\author{
Tomoko Takamiya, ${ }^{1,2,3}$ Saeko Hosobuchi, ${ }^{1,2}$ Tomotsugu Noguchi, ${ }^{1,2}$ Andrew H. Paterson, ${ }^{4}$ \\ Hiroshi Iijima, ${ }^{3}$ Yasufumi Murakami, ${ }^{2}$ and Hisato Okuizumi ${ }^{1}$ \\ ${ }^{1}$ Division of Genome and Biodiversity Research, National Institute of Agrobiological Sciences (NIAS), \\ Tsukuba, Ibaraki 305-8602, Japan \\ ${ }^{2}$ Department of Biological Science \& Technology, Faculty of Industrial Science \& Technology, Tokyo University of Science, \\ Noda, Chiba 278-8510, Japan \\ ${ }^{3}$ College of Pharmacy, Nihon University, Funabashi, Chiba 274-8555, Japan \\ ${ }^{4}$ Plant Genome Mapping Laboratory, University of Georgia, 162R C A G T, Athens, GA 30605, USA
}

Correspondence should be addressed to Hisato Okuizumi, okuizumi@affrc.go.jp

Received 29 May 2009; Revised 29 August 2009; Accepted 26 October 2009

Recommended by Jeffrey Bennetzen

We analyzed inheritance of DNA methylation in reciprocal $\mathrm{F}_{1}$ hybrids (subsp. japonica cv. Nipponbare $\times$ subsp. indica cv. Kasalath) of rice (Oryza sativa L.) using restriction landmark genome scanning (RLGS), and detected differing RLGS spots between the parents and reciprocal $\mathrm{F}_{1}$ hybrids. MspI/HpaII restriction sites in the DNA from these different spots were suspected to be heterozygously methylated in the Nipponbare parent. These spots segregated in $\mathrm{F}_{1}$ plants, but did not segregate in selfed progeny of Nipponbare, showing non-Mendelian inheritance of the methylation status. As a result of RT-PCR and sequencing, a specific allele of the gene nearest to the methylated sites was expressed in reciprocal $F_{1}$ plants, showing evidence of biased allelic expression. These results show the applicability of RLGS for scanning of non-Mendelian inheritance of DNA methylation and biased allelic expression.

Copyright (c) 2009 Tomoko Takamiya et al. This is an open access article distributed under the Creative Commons Attribution License, which permits unrestricted use, distribution, and reproduction in any medium, provided the original work is properly cited.

\section{Introduction}

DNA methylation is very common in mammals and plants and plays an important role in the regulation of gene expression. For example, allele-specific DNA methylation regulates monoallelic expression, such as genomic imprinting [1$3]$, X-chromosome inactivation [4, 5], autosomal random monoallelic expression [6,7], and allelic exclusion [8]. The methylation status in these phenomena is altered or inherited in a specific manner during development, growth, and reproduction. In mammals, DNA methylation patterns throughout the genome change dramatically during tumourigenesis [9], gametogenesis [10], or early development [11]. For example, imprinted genes are regulated by methylation of a differentially methylated region, and the allele-specific methylation pattern in the differentially methylated region is established in the germ cell line after erasing imprinting memory by demethylation [11]. In contrast, in plants, the methylation status of some genes is stably inherited through meiosis [12, 13]. Recent studies [14-16] have shown that methylation patterns can be altered in plant hybrids by introgression, and in allopolyploids. However, generational changes in methylation status and its inheritance in plants have remained unclear.

Restriction landmark genome scanning (RLGS) employs two-dimensional electrophoresis (2DE) of genomic DNA, which allows visualization of thousands of loci [17-20]. This method is appropriate for genome-wide methylation surveys [21-24]. We analyzed the inheritance of DNA methylation in the first filial generation (F1) hybrid between Oryza sativa L. subsp. japonica cv. Nipponbare and subsp. indica cv. Kasalath by RLGS, and detected altered inheritance and 
demethylation of specific RLGS spots in F1 plants [25]. In this study, we analyzed the appearance or disappearance of two altered spots in reciprocal F1 hybrids and selfed progeny, and detected an unexpected allelic expression bias.

\section{Materials and Methods}

2.1. Plant Materials and DNA Preparation. Seeds of Oryza sativa L. subsp. japonica cv. Nipponbare and subsp. indica cv. Kasalath were sown and grown in the field. Reciprocal hybrids were produced by crossing the same individual of each cultivar as the female parent on one culm and as the male parent on another culm. Crossing Nipponbare as the seed parent with Kasalath as the pollen parent gave $\mathrm{F}_{1}$ hybrids designated $\mathrm{NKF}_{1}$. The converse cross gave $\mathrm{KNF}_{1}$ hybrids. We grew plants of Nipponbare, Kasalath, $\mathrm{NKF}_{1}$ (nine individuals from the same parents), and $\mathrm{KNF}_{1}$ (nine individuals from the same parents), and the selfed progeny of the parents for 2 months, and then isolated the genomic DNA of each from the leaf blade and sheath by a standard CTAB extraction method [26].

2.2. RLGS and Identification of Target Spots. The methylation status of the parental Nipponbare and Kasalath, $9 \mathrm{NKF}_{1}$ plants (NK1 to NK9), and $9 \mathrm{KNF}_{1}$ plants (KN1 to KN9) was analyzed by an RLGS method with combinations of NotI-MspI-BamHI (hereafter [MspI] pattern) or NotIHpaII-BamHI ([HpaII] pattern) restriction enzymes [22, 25]. Briefly, $0.4 \mu \mathrm{g}$ of genomic DNA was treated with 2 U DNA polymerase I (Nippon Gene, Tokyo, Japan) in $10 \mu \mathrm{L}$ of blocking buffer ( $10 \mathrm{mM}$ Tris- $\mathrm{HCl}, \mathrm{pH} 7.4,10 \mathrm{mM}$ $\mathrm{MgCl}_{2}, 1 \mathrm{mM}$ dithiothreitol (DTT), $0.4 \mu \mathrm{M}$ dGTP, $0.2 \mu \mathrm{M}$ dCTP, $0.4 \mu \mathrm{M}$ ddATP, and $0.4 \mu \mathrm{M}$ ddTTP) at $37^{\circ} \mathrm{C}$ for 20 minutes. Next, to inactivate DNA polymerase $\mathrm{I}$, the sample was incubated at $65^{\circ} \mathrm{C}$ for 30 minutes. Thereafter, the genomic DNA was digested with $20 \mathrm{U}$ NotI (NEB, Beverly, MA, USA) in a volume of $20 \mu \mathrm{L}$, then the digested DNA was end-labeled by filling reaction with Sequenase ver. 2.0 (USB, Cleveland, OH, USA) in the presence of $0.33 \mu \mathrm{M}\left[\alpha_{-}{ }^{32} \mathrm{P}\right] \mathrm{dGTP}(3,000 \mathrm{Ci} / \mathrm{mmol}), 0.33 \mu \mathrm{M}\left[\alpha_{-}{ }^{32} \mathrm{P}\right]$ $\mathrm{dCTP}(6,000 \mathrm{Ci} / \mathrm{mmol})$, and $1.3 \mathrm{mM} \mathrm{DTT}$ at $37^{\circ} \mathrm{C}$ for 30 minutes. Thereafter, this reaction mixture was incubated at $65^{\circ} \mathrm{C}$ for 30 minutes to inactivate the enzyme. The sample was divided into two tubes. One was digested with $25 \mathrm{U}$ MspI (Toyobo, Tokyo, Japan), and the other was treated with $25 \mathrm{U} \mathrm{HpaII}$ (Toyobo) at $37^{\circ} \mathrm{C}$ for 1 hour. Each sample was fractionated on an agarose disc gel (0.8\% SeaKem GTG agarose, FMC Bioproducts, Rockland, ME, USA) in a $2.4 \mathrm{~mm}$ diameter $\times 63 \mathrm{~cm}$ long tube, and then electrophoresed in the 1st-dimensional (1-D) buffer (0.1 M Tris-acetate, $\mathrm{pH} 8.0$, $40 \mathrm{mM}$ sodium acetate, $3 \mathrm{mM}$ EDTA, $\mathrm{pH} 8.0,36 \mathrm{mM} \mathrm{NaCl}$ ) at $100 \mathrm{~V}$ for 1 hour followed by $230 \mathrm{~V}$ for 23 hours. After 1$\mathrm{D}$ electrophoresis, the gel was extruded from the tube and soaked for 30 minutes in the reaction buffer for $B a m \mathrm{HI}$, and then the DNA in the gel was digested with $1500 \mathrm{U}$ BamHI for 2 hours. The gel was fused onto the top edge of a $50 \mathrm{~cm}$ (W) $\times 50 \mathrm{~cm}(\mathrm{H}) \times 0.1 \mathrm{~cm}(\mathrm{~T}) 5 \%$ vertical polyacrylamide gel using melted agarose $(0.8 \%)$ to connect the gels. The 2 nddimensional (2-D) electrophoresis parameters were Trisborate-EDTA (TBE) buffer (50 mM Tris, $62 \mathrm{mM}$ boric acid, $1 \mathrm{mM}$ EDTA), at $100 \mathrm{~V}$ for 1 hour followed by $150 \mathrm{~V}$ for 23 hours. An area of $35 \mathrm{~cm} \times 41 \mathrm{~cm}$ of the original gel was excised and dried. Autoradiography was performed for 3-10 days on film (XAR-5; Kodak, Rochester, NY, USA) at $-80^{\circ} \mathrm{C}$ using an intensifying screen (Quanta III; Sigma-Aldrich, St. Louis, MO, USA), or for 1-3 days on an imaging plate (Fuji Photo Film, Tokyo, Japan). Finally, the imaging plate was analyzed by a BAS-2000 scanner (Fuji Photo Film). MspI and HpaII are restriction enzymes that recognize the same sequence, but have different methylation sensitivity. When the second $\mathrm{C}$ of the sequence $\mathrm{CCGG}$ is methylated ( $\mathrm{C}^{m} \mathrm{CGG}$ ), MspI, but not HpaII, cleaves the site. Conversely, neither MspI nor HpaII digests ${ }^{m} \mathrm{C}^{m} \mathrm{CGG}$ or ${ }^{m}$ CCGG. Differences between $[M s p \mathrm{I}]$ and $[H p a I I]$ patterns indicate a methylated CpG ( $\left.\mathrm{C}^{m} \mathrm{CGG}\right)$ at an MspI/HpaII site.

Target spots were identified using in silico RLGS computer software $[22,25]$, which simulates RLGS analysis of genome sequence data. The software calculates the length and mobility of each DNA fragment from the Not I to MspI end or to the next NotI end in a 1D gel, and the DNA fragment length from the NotI to BamHI end in a $2 \mathrm{D}$ gel to produce a $2 \mathrm{D}$ pattern (in silico RLGS pattern). We compared autoradiographic RLGS patterns with corresponding in silico RLGS patterns and identified each RLGS spot. The spots unidentified by in silico RLGS analysis were cloned and sequenced as previously described $[22,25]$ with specific cloning linkers: Not I linker (5'-GGCCGCATGAATGGCGCGCCAAAGA-3', 3' CGTACTTACCGCGCGGTTTCT-biotin-5') and BamHI linker (5'-GATCCTGTACTGCACCAGCAAATCC-3', 3' GACATGACGTGGTCGTTTAGG-5' ).

\subsection{Confirmation of Restriction Enzyme Sites by Digestion} and PCR-Based DNA Methylation Analysis of Target Spots. To compare methylation status among Nipponbare, Kasalath, and their $\mathrm{F}_{1} \mathrm{~s}$, we confirmed the presence of restriction enzyme sites in the parents. We designed flanking primers for the NotI and MspI/HpaII sites of each RLGS spot. Using $1 \mathrm{ng}$ Nipponbare or Kasalath genomic DNA as a template, PCR was carried out with $0.4 \mathrm{U}$ KOD plus polymerase (Toyobo,), $1.5 \mu \mathrm{L}$ flanking primers $(10 \mathrm{pmol} / \mu \mathrm{L}), 1 \mathrm{mM}$ $\mathrm{MgSO}_{4}, 0.2 \mathrm{mM}$ dNTPs, and KOD buffer (total volume $20 \mu \mathrm{L})$. PCR conditions were $94^{\circ} \mathrm{C}$ for 5 minutes followed by 30 cycles of $94^{\circ} \mathrm{C}$ for $15 \mathrm{~s}, 60^{\circ} \mathrm{C}$ for $30 \mathrm{~s}$, and $68^{\circ} \mathrm{C}$ for 1 minutes. An aliquot of each PCR product was treated with NotI or MspI. Then untreated and treated products were electrophoresed in an agarose gel (0.8\%-3.0\%), and the band sizes were compared to confirm that the sites were present and did not differ by any DNA size polymorphism. Next, we confirmed the methylation status of the NotI and MspI/HpaII sites of the RLGS spot. Genomic DNA (1 ng) of Nipponbare, Kasalath, or the reciprocal $\mathrm{F}_{1} \mathrm{~s}$ was digested with $30 \mathrm{U}$ NotI, MspI, or HpaII, and used as a PCR template. Undigested genomic DNA was used as a positive control. PCR was performed as described above. 


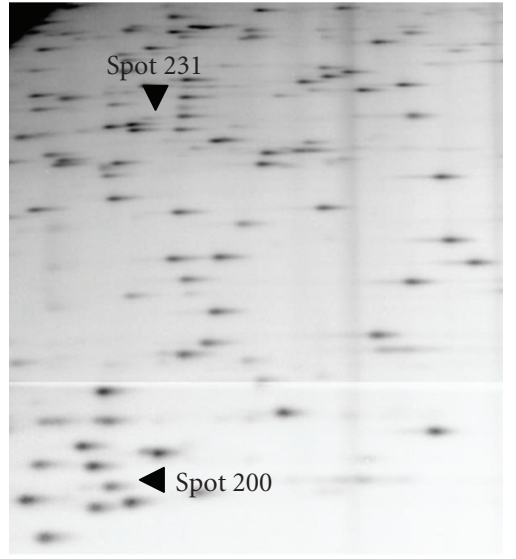

(a)

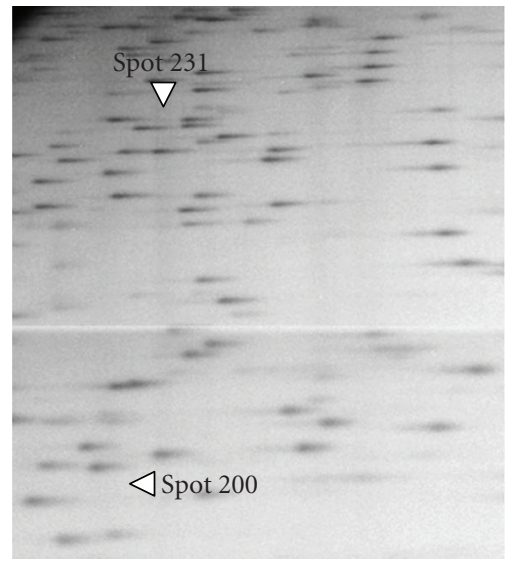

(b)

Figure 1: RLGS [MspI] (NotI-MspI-BamHI) patterns of rice genomic DNA. Comparison of Nipponbare and Kasalath patterns revealed Nipponbare and Kasalath specific spots. (a) Nipponbare pattern. Spots 200 and 231 were detected at diminished spot intensities and are indicated by closed arrowheads. (b) Kasalath pattern. Neither spots 200 nor 231 were not detected.

2.4. Total RNA Isolation and Expression Analysis by RT-PCR. Using an RNeasy Plant Mini Kit (Qiagen, Tokyo, Japan), total RNA was isolated from the leaf blade and sheath of the same parents, NK5, NK7, KN5, and KN10. The 4 reciprocal $\mathrm{F}_{1}$ hybrids were chosen because two target RLGS spots (200 and 231) were detected in NK5 and KN5, but not in NK7 and KN10. First-strand cDNA was synthesized from 50 ng DNAfree samples with a ReverTra-Plus RT-PCR Kit (Toyobo, Osaka, Japan). The cDNA was used for RT-PCR analysis of each target gene. For spot 200, we used forward primer $5^{\prime}$-CACATCCTGATCACCGTCCA-3' and reverse primer $5^{\prime}$-GTCCCAACCCGTGATCAAGTT-3'. For spot 231, we used forward primer $5^{\prime}$-ACTCAGGCTCAGATCGCCAT-3' and reverse primer $5^{\prime}$-CCCGAGCTCCGTTTAGCATA- $3^{\prime}$. Actin 1 was used as an internal standard (forward primer: 5'-TATGGTCAAGGCTGGGTTCG-3', reverse primer: $5^{\prime}$ AACACAATACCTTGGGTACG-3'). PCR for each gene followed an initial denaturation for 2 minutes at $94^{\circ} \mathrm{C}$, then

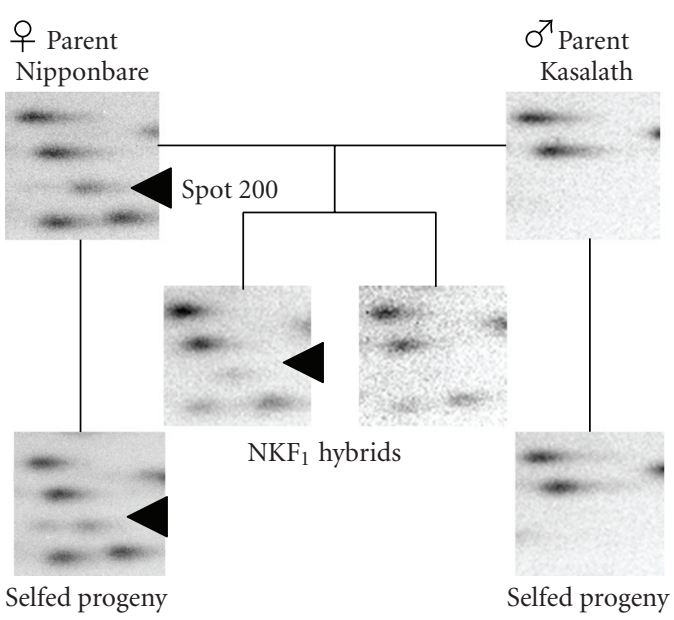

(a)

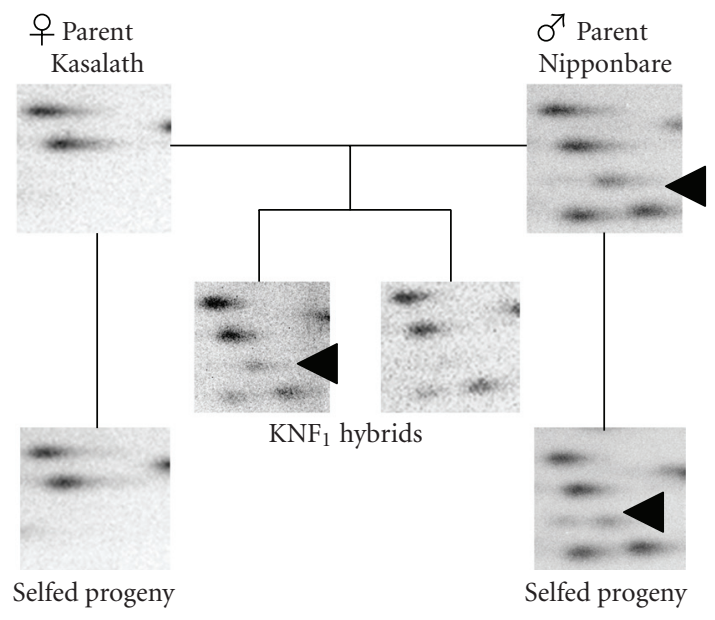

(b)

Figure 2: RLGS [MspI] (NotI-MspI-BamHI) combination patterns of the parents, their selfed progeny, and their reciprocal $\mathrm{F}_{1}$ hybrids. Spot 200 (arrowhead) was detected in the $[\mathrm{MspI}]$ patterns (Figure 1) and [HpaII] (NotI-HpaII-BamHI) patterns (data not shown) of Nipponbare and its selfed progeny. The presence or absence of the spot segregated in both $\mathrm{F}_{1}$ populations $\left(\mathrm{NKF}_{1}\right.$ and $\left.\mathrm{KNF}_{1}\right)$. The spot intensity of this spot was half that of the others.

37 cycles of $10 \mathrm{~s}$ at $98^{\circ} \mathrm{C}, 30 \mathrm{~s}$ at $60^{\circ} \mathrm{C}$, and $20 \mathrm{~s}$ at $68^{\circ} \mathrm{C}$. The PCR products were analyzed by electrophoresis followed by ethidium bromide staining.

\section{Results and Discussion}

Analysis of the RLGS patterns of the parents and the reciprocal hybrids showed variations in some spots between samples, reflecting changes in DNA methylation. One such altered spot was spot 200, which was detected in both the [MspI] and [HpaII] patterns of Nipponbare at a diminished spot intensity (half the intensity of the surrounding spots), but was absent in Kasalath (Figures 1 and 2). Cloning and sequencing of this DNA fragment placed it in the $5^{\prime}$ region of a non-protein coding transcript (Os11g0417300) (Figure 3). 


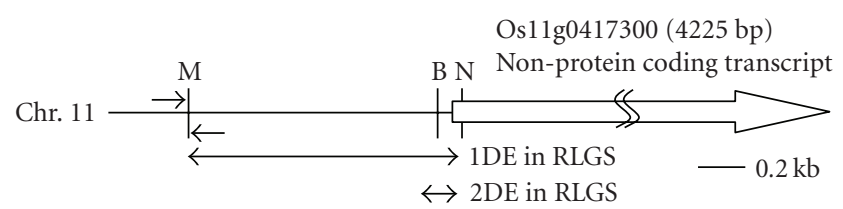

Figure 3: Location of spot 200. Schematic of the region of chromosome 11 containing the restriction enzyme sites located in the region $5^{\prime}$ to the transcription start site of the non-protein coding transcript (Os11g0417300). The DNA fragments were digested at the $\operatorname{Not} \mathrm{I}(\mathrm{N})$ and MspI/HpaII (M) sites and fractionated by one dimensional electrophoresis. Next, the DNA fragments that were digested at the BamHI (B) sites were fractionated by two dimensional electrophoresis, which allowed detection of the B-N fragment as an RLGS spot. Spot 200 corresponds to the fragment between the $\mathrm{N}$ and $\mathrm{B}$ sites. The $\mathrm{N}$ and $\mathrm{M}$ sites were identified in the parental Nipponbare and Kasalath, and in both reciprocal hybrids. The B site was only absent in Kasalath, resulting in the absence of spot 200 in the RLGS pattern.

Comparison of the relative spot positions between autoradiographic RLGS patterns of the parental Nipponbare and in silico RLGS pattern derived from Nipponbare genome sequence data revealed that the DNA fragments digested at the $\operatorname{Not} \mathrm{I}(\mathrm{N})$ and $M s p \mathrm{I}(\mathrm{M})$ sites were fractionated by 1-D electrophoresis, and the DNA fragments digested at the $\mathrm{N}$ and BamHI (B) sites were fractionated by 2-D electrophoresis as spot 200 (Figure 3). By restriction enzyme digestion and sequencing, we confirmed the existence of $\mathrm{N}$, $M$, and $B$ in the parental Nipponbare (data not shown). In the parental Kasalath, there were $\mathrm{N}$ and $\mathrm{M}$ sites, but no B site (data not shown). The results of RLGS analysis of the $\mathrm{NKF}_{1}$ and $\mathrm{KNF}_{1}$ hybrids showed that the presence or absence of spot 200 segregated 1:1 in both populations (Figure 2 and Table 1). The diminished spot intensity in the parental Nipponbare and its segregation in $\mathrm{F}_{1}$ hybrids imply that the MspI/HpaII site of spot 200 is methylated heterozygously in Nipponbare. Accordingly, it was assumed that spot 200 was detected in the $F_{1}$ individuals that had a non-methylated $M$ site, and not detected in the $F_{1}$ individuals that had a methylated M site. Additionally, spot 200 was detected in all selfed progeny (nine individuals) of Nipponbare at half intensity (Figure 2 and Table 1). In RLGS analysis, halved intensity of a spot indicates a heterozygote, which was confirmed theoretically and practically in earlier studies $[27,28]$. From this observation, it was assumed that the M site was methylated heterozygously in the selfed progeny as well as the parental Nipponbare because of non-Mendelian inheritance of methylation.

We suspected that the methylation status correlated with expression of the nearest gene. Therefore, we analyzed the expression of the non-protein coding transcript (Os11g0417300) that is the nearest gene to the MspI/HpaII site of spot 200 (Figure 3). The cDNA (GenBank accession No. AK109537) of the non-protein coding transcript, which was previously isolated, is expressed in flower, leaf, and panicle (http://www.ncbi.nlm.nih.gov/sites/entrez?db=unigene\& $\mathrm{cmd}=$ search\&term=AK109537). We analyzed expression of the gene by RT-PCR. Total RNA was isolated from the

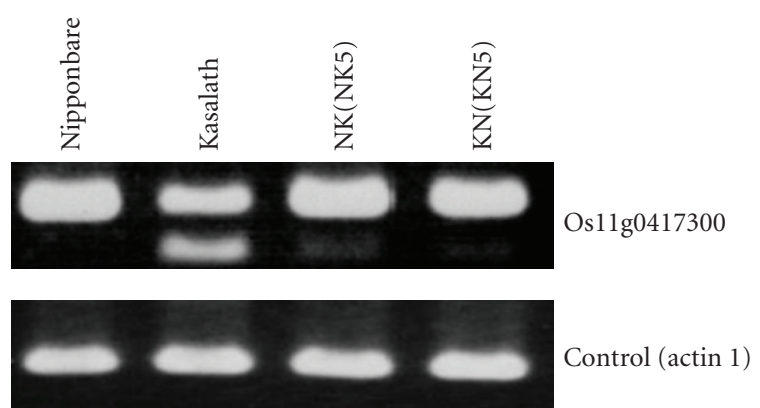

(a)
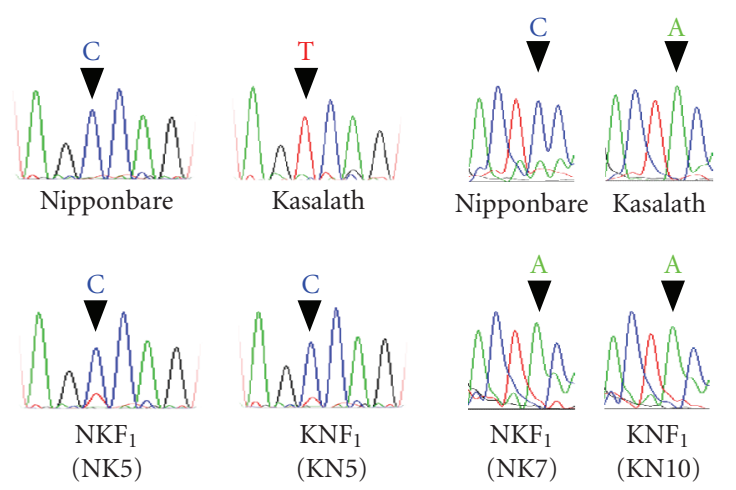

(b)

(c)

FIGURE 4: Expression analysis of the nearest gene to the methylated site. (a) RT-PCR showed that a non-protein coding transcript (Os11g0417300) was expressed in leaf blade and sheath of Nipponbare, Kasalath, $\mathrm{NKF}_{1}$, and $\mathrm{KNF}_{1}$ plants. (b) Sequence analysis of the RT-PCR products of the expressed Os11g0417300 allele. The single nucleotide polymorphism between Nipponbare (C) and Kasalath $(\mathrm{T})$ is indicated in the RT-PCR products by arrowheads. Specific expression of the Nipponbare allele was confirmed by detection of base C in both NK5 and KN5 plants. (c) Sequence analysis of RT-PCR products of the expressed Os01g0327900 allele. The single nucleotide polymorphism in RT-PCR products between Nipponbare (C) and Kasalath (A) is indicated by arrowheads. Specific expression of the Kasalath allele was confirmed by detection of base A in both NK7 and KN10 plants.

leaf blade and sheath of the parental Nipponbare, parental Kasalath, two $\mathrm{NKF}_{1}$ individuals (NK5 and NK7), and two $\mathrm{KNF}_{1}$ individuals (KN5 and KN10). Spot 200 was detected in the patterns of NK5 and KN5, but not in the patterns of NK7 and KN10. The cDNAs were PCR-amplified and separated by agarose gel electrophoresis (Figure 4(a)). The non-protein coding transcript was expressed in the leaf blade and sheath of the parents, $\mathrm{NKF}_{1} \mathrm{~s}$, and $\mathrm{KNF}_{1} \mathrm{~s}$ (data for NK7 and KN10 are not shown but gave the same result). Next, we sequenced the RT-PCR products to reveal the parental origin of the expressed sequence in the $\mathrm{F}_{1}$ hybrids. The presence of a single nucleotide polymorphism (C/T) between Nipponbare and Kasalath allowed this distinction to be made. Sequence analysis of the RT-PCR products from NK5 and KN5, which had spot 200 in their RLGS patterns, showed allelic expression bias for the Nipponbare allele (Figure 4(b)); analysis of NK7 and KN10, which did not have spot 200, also showed bias (data not shown but gave the same 
TABLE 1: Summary of RLGS pattern of spot 200.

\begin{tabular}{|c|c|c|c|}
\hline \multirow{2}{*}{ Generation } & & \multicolumn{2}{|c|}{ RLGS pattern of spot 200} \\
\hline & & MspI patterns (intensity) & HpaII patterns (intensity) \\
\hline Parent & Nipponbare & Present $(1 / 2)$ & Present $(1 / 2)$ \\
\hline Parent & Kasalath & Absent & Absent \\
\hline $\begin{array}{l}\text { Selfed progeny } \\
\text { (9 individuals) }\end{array}$ & Nipponbare & Present (1/2) & Present (1/2) \\
\hline $\begin{array}{l}\text { Selfed progeny } \\
\text { ( } 4 \text { individuals) }\end{array}$ & Kasalath & Absent & Absent \\
\hline $\mathrm{NKF}_{1}$ (9 individuals) & Nipponbare $\times$ Kasalath & $\begin{array}{c}\text { Segregated5 present: } 4 \text { absent } \\
(1 / 2: 0)\end{array}$ & $\begin{array}{c}\text { Segregated } 4 \text { present: } 5 \text { absent } \\
(1 / 2: 0)\end{array}$ \\
\hline $\mathrm{KNF}_{1}$ (9 individuals) & Kasalath $\times$ Nipponbare & $\begin{array}{c}\text { Segregated7 present: } 2 \text { absent } \\
(1 / 2: 0)\end{array}$ & $\begin{array}{c}\text { Segregated } 4 \text { present: } 5 \text { absent } \\
(1 / 2: 0)\end{array}$ \\
\hline
\end{tabular}

result). The bias in the reciprocal hybrids was strong, and implied monoallelic expression of the Nipponbare allele. In addition, we detected a Kasalath-specific splicing variant as a smaller transcript with an expression level lower than that of the Nipponbare allele. This transcript was absent in $\mathrm{NKF}_{1}$ and $\mathrm{KNF}_{1}$. Sequencing this transcript revealed a splicing variant that leads to a 76-bp deletion at the $3^{\prime}$ end of exon 2 .

The non-Mendelian spot 231 showed the same behavior as spot 200 on RLGS. The spot intensity was half that of the surrounding spots and the presence or absence of this spot also segregated 1: 1 in $\mathrm{NKF}_{1}$ and $\mathrm{KNF}_{1}$. Additionally, spot 231, like spot 200, was detected in all selfed progeny of Nipponbare. We similarly analyzed the expression of the nearest gene (DUF295 family protein Os01g0327900) in two $\mathrm{NKF}_{1}$ (NK5 and NK7) and two $\mathrm{KNF}_{1}$ (KN5 and KN10) individuals. Sequence analysis of the RT-PCR products showed that only the Kasalath allele was expressed in NK5, NK7, KN5, and KN10 (Figure 4(c) shows the results for NK7 and $\mathrm{KN} 10$; data for NK5 and KN5 are not shown but gave the same result). In this study, we have given two examples of the nearest gene to a heterozygous methylated site showing allelic expression bias.

Recently, monoallelic expression in $\mathrm{F}_{1}$ hybrids of plants has been reported. Zhuang and Adams [29] reported that in Populus interspecific hybrids, 17 out of 30 genes analyzed showed $>1.5$-fold expression bias for one of two alleles, with monoallelic expression of one gene [29], while intraspecific maize hybrids have shown unequal expression of parental alleles [30-32]. Therefore, histone modification or DNA methylation is considered one cause of allelic expression bias.

Elucidation of the significance and mechanism of regulation of monoallelic expression requires detection of more RLGS spots showing non-Mendelian inheritance along with the analysis of the methylation status of the corresponding DNA sequence and the expressed allele. Further expression analyses of genes in $\mathrm{F}_{1}$ s having different genetic backgrounds will support our findings for application to other genes. Moreover, revealing the function of the splicing variant of Kasalath in $\mathrm{F}_{1}$ hybrids may provide better understanding of the mechanism of allelic exclusion inducing heterosis, hybrid weakness, and genome barriers.

\section{Conclusion}

Our findings clearly demonstrate that the RLGS method can be successfully applied to survey non-Mendelian inheritance of DNA methylation. Consequently, we detected two loci showing non-Mendelian inheritance and allelic expression bias in $\mathrm{F}_{1}$ hybrids of rice. The systematic scanning has the following advantages: (1) easy detection of candidates for non-Mendelian inheritance of DNA methylation by simple comparison of spot patterns between parents and $\mathrm{F}_{1}$ hybrids, (2) low cost and quick yield results in only 3 days, and (3) detection of potentially more non-Mendelian spot candidates using different restriction enzyme combinations in RLGS.

\section{Acknowledgments}

The authors thank M. Kawase, K. Tomioka, Y. Habu, T. Ueda, and S. Takahashi of the National Institute of Agrobiological Sciences for their advice and technical support. This work was supported by a grant from the Japanese Ministry of Agriculture, Forestry and Fisheries to Histao OKuizumi.

\section{References}

[1] S. Tiwari, R. Schulz, Y. Ikeda, et al., "MATERNALLY EXPRESSED PAB C-TERMINAL, a novel imprinted gene in Arabidopsis, encodes the conserved C-terminal domain of polyadenylate binding proteins," The Plant Cell, vol. 20, no. 9, pp. 2387-2398, 2008.

[2] M. K. Nowack, R. Shirzadi, N. Dissmeyer, et al., "Bypassing genomic imprinting allows seed development," Nature, vol. 447, no. 7142, pp. 312-315, 2007.

[3] E. Daura-Oller, M. Cabre, M. A. Montero, J. L. Paternain, and A. Romeu, "A first-stage approximation to identify new imprinted genes through sequence analysis of its coding regions," Comparative and Functional Genomics, vol. 2009, Article ID 549387, 7 pages, 2009.

[4] P. Avner and E. Heard, "X-chromosome inactivation: counting, choice and initiation," Nature Reviews Genetics, vol. 2, no. 1, pp. 59-67, 2001.

[5] Y. Shen, Y. Matsuno, S. D. Fouse, et al., "X-inactivation in female human embryonic stem cells is in a nonrandom 
pattern and prone to epigenetic alterations," Proceedings of the National Academy of Sciences of the United States of America, vol. 105, no. 12, pp. 4709-4714, 2008.

[6] Y. Sano, T. Shimada, H. Nakashima, et al., "Random monoallelic expression of three genes clustered within $60 \mathrm{~kb}$ of mouse t complex genomic DNA," Genome Research, vol. 11, no. 11, pp. 1833-1841, 2001.

[7] A. Gimelbrant, J. N. Hutchinson, B. R. Thompson, and A. Chess, "Widespread monoallelic expression on human autosomes," Science, vol. 318, no. 5853, pp. 1136-1140, 2007.

[8] S. Fraenkel, R. Mostoslavsky, T. I. Novobrantseva, et al., "Allelic 'choice' governs somatic hypermutation in vivo at the immunoglobulin $\kappa$-chain locus," Nature Immunology, vol. 8, no. 7, pp. 715-722, 2007.

[9] M. Zeschnigk, F. Tschentscher, C. Lich, B. Brandt, B. Horsthemke, and D. R. Lohmann, "Methylation analysis of several tumour suppressor genes shows a low frequency of methylation of CDKN2A and RARB in uveal melanomas," Comparative and Functional Genomics, vol. 4, no. 3, pp. 329336, 2003.

[10] M. Monk, M. Boubelik, and S. Lehnert, "Temporal and regional changes in DNA methylation in the embryonic, extraembryonic and germ cell lineages during mouse embryo development," Development, vol. 99, no. 3, pp. 371-382, 1987.

[11] S. Tada, T. Tada, L. Lefebvre, S. C. Barton, and M. A. Surani, "Embryonic germ cells induce epigenetic reprogramming of somatic nucleus in hybrid cells," The EMBO Journal, vol. 16, no. 21, pp. 6510-6520, 1997.

[12] S. E. Jacobsen and E. M. Meyerowitz, "Hypermethylated SUPERMAN epigenetic alleles in Arabidopsis," Science, vol. 277, no. 5329, pp. 1100-1103, 1997.

[13] T. Kakutani, K. Munakata, E. J. Richards, and H. Hirochika, "Meiotically and mitotically stable inheritance of DNA hypomethylation induced by ddm1 mutation of Arabidopsis thaliana," Genetics, vol. 151, no. 2, pp. 831-838, 1999.

[14] Y. Xu, L. Zhong, X. Wu, X. Fang, and J. Wang, "Rapid alterations of gene expression and cytosine methylation in newly synthesized Brassica napus allopolyploids," Planta, vol. 229, no. 3, pp. 471-483, 2009.

[15] Z. Liu, Y. Wang, Y. Shen, W. Guo, S. Hao, and B. Liu, "Extensive alterations in DNA methylation and transcription in rice caused by introgression from Zizania latifolia," Plant Molecular Biology, vol. 54, no. 4, pp. 571-582, 2004.

[16] H. R. Woo and E. J. Richards, "Natural variation in DNA methylation in ribosomal RNA genes of Arabidopsis thaliana," BMC Plant Biology, vol. 8, article 92, 2008.

[17] Y. Hayashizaki, S. Hirotsune, Y. Okazaki, et al., "Restriction landmark genomic scanning method and its various applications," Electrophoresis, vol. 14, no. 4, pp. 251-258, 1993.

[18] H. Yoshikawa, H. Nagai, K. Matsubara, and A. Fujiyama, "Two-dimensional gel electrophoretograms of human chromosome specific restriction DNA fragments," Biochemical and Biophysical Research Communications, vol. 196, no. 3, pp. 1566-1572, 1993.

[19] H. Okamoto, T. Takamiya, A. Saito, et al., "Development of a new cultivar-discrimination method based on DNA polymorphism in a vegetatively propagated crop," Japan Agricultural Research Quarterly, vol. 40, no. 1, pp. 65-69, 2006.

[20] H. Ichida, K. Maeda, H. Ichise, et al., "In silico restriction landmark genome scanning analysis of Xanthomonas oryzae pathovar oryzae MAFF 311018," Biochemical and Biophysical Research Communications, vol. 363, no. 3, pp. 852-856, 2007.

[21] Y. Hayashizaki, H. Shibata, S. Hirotsune, et al., "Identification of an imprinted U2af binding protein related sequence on mouse chromosome 11 using the RLGS method," Nature Genetics, vol. 6, no. 1, pp. 33-40, 1994.

[22] T. Takamiya, S. Hosobuchi, K. Asai, et al., "Restriction landmark genome scanning method using isoschizomers (Mspl/Hpall) for DNA methylation analysis," Electrophoresis, vol. 27, no. 14, pp. 2846-2856, 2006.

[23] T. Takamiya, Y. Ohtake, S. Hosobuchi, et al., "Application of RLGS method for detection of alteration in tissue cultured plants," Japan Agricultural Research Quarterly, vol. 42, no. 3, pp. 151-155, 2008.

[24] J. F. Costello, C. Hong, C. Plass, and D. J. Smiraglia, "Restriction landmark genomic scanning: analysis of CpG islands in genomes by 2D gel electrophoresis," Methods in Molecular Biology, vol. 507, pp. 131-148, 2009.

[25] T. Takamiya, S. Hosobuchi, T. Noguchi, et al., "Inheritance and alteration of genome methylation in $\mathrm{F}_{1}$ hybrid rice," Electrophoresis, vol. 29, no. 19, pp. 4088-4095, 2008.

[26] M. G. Murray and W. F. Thompson, "Rapid isolation of high molecular weight plant DNA," Nucleic Acids Research, vol. 8, no. 19, pp. 4321-4325, 1980.

[27] Y. Hayashizaki, S. Hirotsune, Y. Okazaki, et al., "A genetic linkage map of the mouse using restriction landmark genomic scanning (RLGS)," Genetics, vol. 138, no. 4, pp. 1207-1238, 1994.

[28] H. Okuizumi, Y. Okazaki, and Y. Hayashizaki, "RLGS spot mapping method," in Restriction Landmark Genomic Scanning (RLGS), Y. Hayashizaki and S. Watanabe, Eds., pp. 57-93, Springer, Tokyo, Japan, 1997.

[29] Y. Zhuang and K. L. Adams, "Extensive allelic variation in gene expression in populus $\mathrm{F}_{1}$ hybrids," Genetics, vol. 177, no. 4, pp. 1987-1996, 2007.

[30] M. Guo, M. A. Rupe, C. Zinselmeier, J. Habben, B. A. Bowen, and O. S. Smith, "Allelic variation of gene expression in maize hybrids," The Plant Cell, vol. 16, no. 7, pp. 1707-1716, 2004.

[31] N. M. Springer and R. M. Stupar, "Allelic variation and heterosis in maize: how do two halves make more than a whole?” Genome Research, vol. 17, no. 3, pp. 264-275, 2007.

[32] N. M. Springer and R. M. Stupar, "Allele-specific expression patterns reveal biases and embryo-specific parent-of-origin effects in hybrid maize," The Plant Cell, vol. 19, no. 8, pp. 23912402, 2007. 

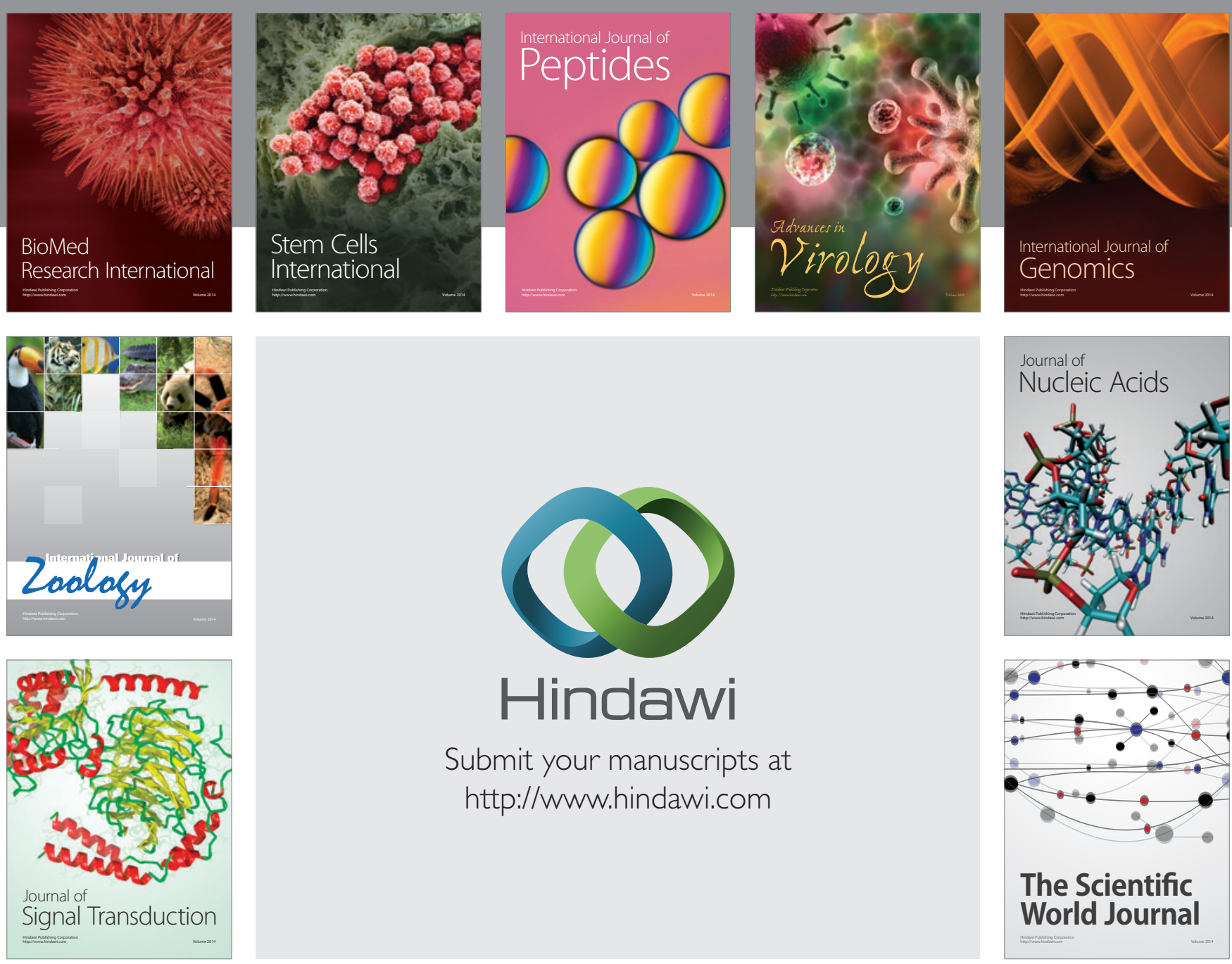

Submit your manuscripts at

http://www.hindawi.com
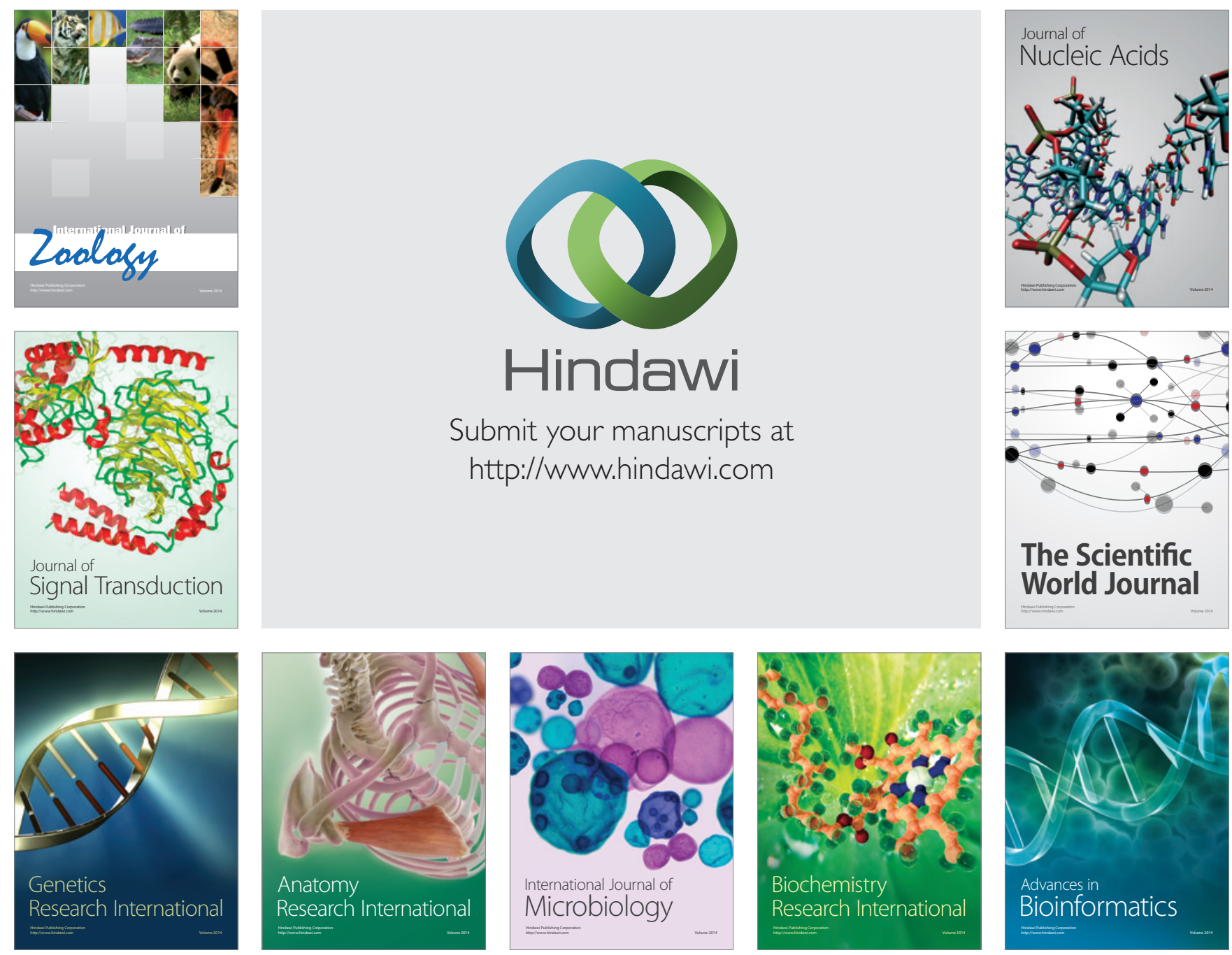

The Scientific World Journal
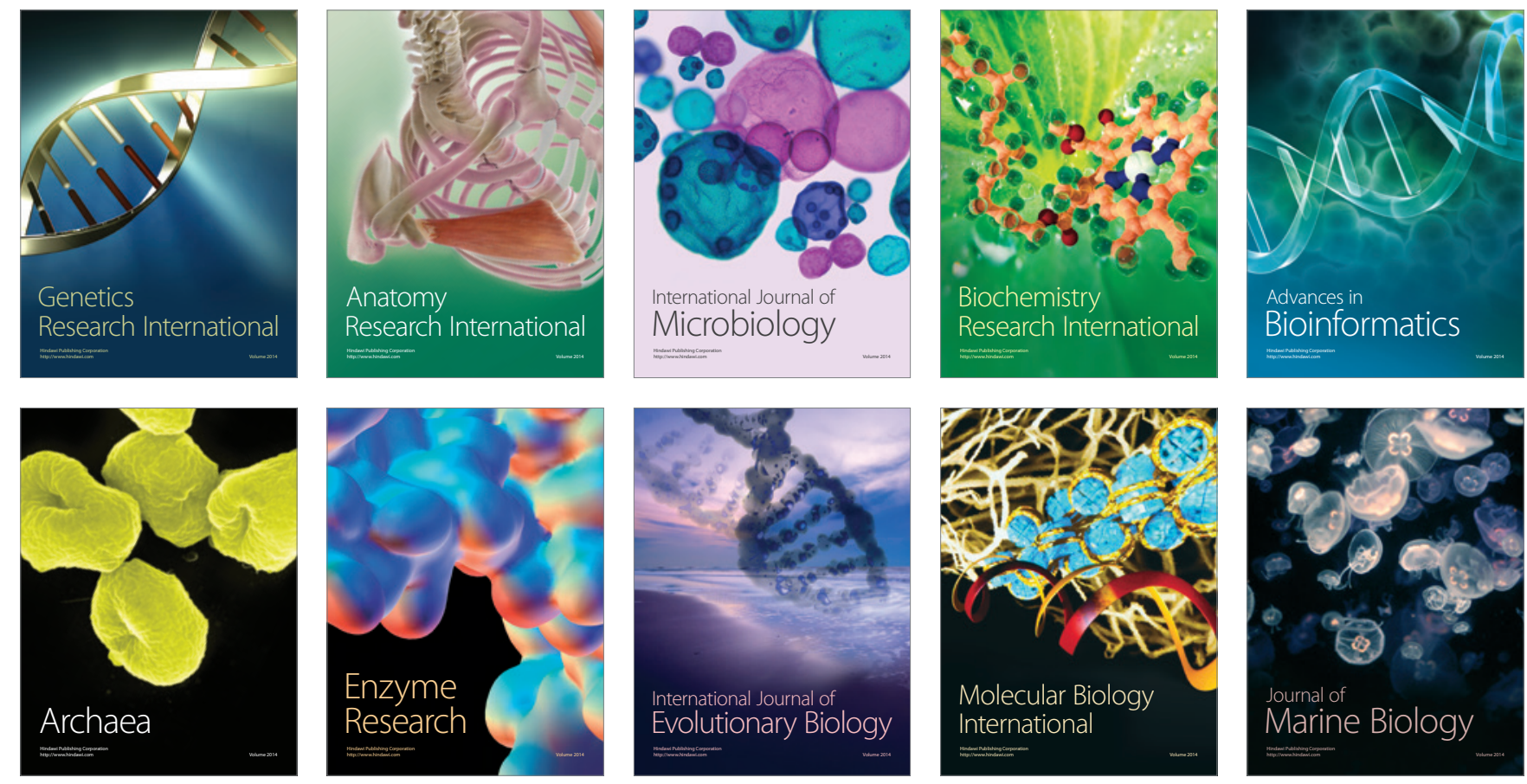